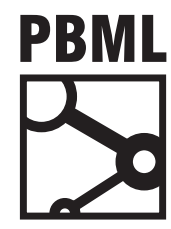

The Prague Bulletin of Mathematical Linguistics

NUMBER 106 OCTOBER $2016 \quad 5-20$

\title{
Against the Argument-Adjunct Distinction in Functional Generative Description
}

\author{
Adam Przepiórkowski ${ }^{a b}$ \\ a Institute of Computer Science, Polish Academy of Sciences \\ b Institute of Philosophy, University of Warsaw
}

\begin{abstract}
The aim of this paper is to critically examine the tests used to distinguish arguments from adjuncts in Functional Generative Description (Sgall et al., 1986) and to question the general usefulness of this distinction. In particular, we demonstrate that neither of the two tests used in FGD to distinguish inner participants from free adverbials (i.e. tests based on iterability and specificity) stands up to scrutiny, and we also point out practical problems with the application of the dialogue test, used to distinguish semantically obligatory and semantically optional dependents. Since these tests are among the most frequently cited tests for the Argument-Adjunct Distinction in contemporary linguistics, these results cast a shadow on the general validity of this dichotomy.
\end{abstract}

\section{Introduction}

Probably all modern linguistic theories assume some form of the ArgumentAdjunct Distinction (AAD), which may be traced back to Lucien Tesnière's (1959) distinction between actants and circumstants: the former are elements of valency frames of respective predicates, while the latter are not. In case of the Functional Generative Description (FGD; Sgall et al. 1986), the relevant classes were at one point (Panevová, 1974, 1978) called inner participants and free adverbials, respectively, but in later FGD works these terms adopted different meanings (see below), so we will use the widespread cross-theoretical terms arguments and adjuncts to distinguish valency dependents from non-valency dependents. Obviously, all these terms are relative to a particular occurrence of a particular predicate: a phrase which is an adjunct to a predicate in one utterance (e.g. that day in I saw John that day; cf. Larson 1985, p. 595) 
may be an argument of another predicate or even of another occurrence of the same predicate: either a complement (I saw that day in my mind) or the subject (That day saw the coronation of Charles IV).

The aim of this paper is to critically examine the tests used to distinguish arguments from adjuncts in FGD, as presented in Panevová 1974, 1978. In particular, we will point out the weaknesses of particular tests used when making this distinction, and of the way they are combined. Some attention will be devoted to the so-called "dialogue test" (Sgall and Hajičová, 1970; Panevová, 1974, 1978); we will show that tests aiming at the same property of dependents have been in another linguistic tradition since around the same time.

\section{AAD in FGD}

Two basic dichotomies play a role in FGD in distinguishing arguments from adjuncts: 1) that between - to use the current FGD terminology - inner participants (called complements in Panevová 1974, 1978) and free adverbials (called simply adverbials in Panevová 1974, 1978), and 2) that between semantically obligatory and semantically optional dependents.

Two tests are used in case of the first dichotomy, between inner participants and free adverbials (Panevová, 1974, p. 11):

(1) "Can the given type of participant [i.e. dependent in our terminology; AP] depend on every verb?"

(2) "Can the given type of participant [i.e. dependent; AP] depend more than once on a single verb token...?"

In the literature on arguments and adjuncts, the former test is known as the specificity criterion (e.g. Koenig et al. 2003), and the latter - as the iterability criterion (e.g. Williams 2015, pp.69-70). For example, time (TWHEN), location (LOC) and manner (MANN) dependents seem to be allowed to occur with almost any verb and they may be iterated, as in the famous example from Bresnan 1982b, p. 164: 1

(3) Fred deftly [MANN] handed a toy to the baby by reaching behind his back [MANN] over lunch [TWHEN] at noon [TWHEN] in a restaurant [LOC] last Sunday [TWHEN] in Back Bay [LOC] without interrupting the discussion [MANN].

The assumption in Panevová 1974 is that these two tests go hand in hand, with the exception of the type of dependent called actor in FGD (roughly, deep subject), which may in principle occur with almost any verb (like free adverbials do) but is not iterable (just like inner participants). While Panevová 1978, pp. 232-233, plays down the iterability criterion (2) and instead relies only on the specificity test (1), iterability is still mentioned in later FGD work, so we will include it in the discussion below.

\footnotetext{
${ }^{1}$ The original annotations Manner, Temp and Loc are substituted here with the FGD functors MANN, TWHEN and LOC, assuming the repertoire of functors listed in Žabokrtský 2005, pp. 117-118.
} 
The other dichotomy used to distinguish arguments from adjuncts concerns semantic obligatoriness, as verified by the dialogue test.? This test may be illustrated on the basis of the verb ARRIVE and used to decide whether the possible ablative (where from) and adlative (where to) dependents are semantically obligatory (and, hence, arguments in the sense used in this paper), even though both are syntactically optional. Let us imagine that A said John arrived. If the dialogue continues by $\mathrm{B}$ asking Where from? and A answering I don't know, there is nothing particular about the dialogue. However, if B asks Where? and A answers I don't know, there is something funny about it: how could have A said John arrived if he cannot answer the question where John arrived? Perhaps a different verb should have been used by A. Hence, according to this test, the adlative dependent, unlike the ablative dependent, is semantically obligatory.

Given these two distinctions: inner participants vs. free adverbials and semantically obligatory vs. semantically not obligatory, arguments are in practice - although not in these exact words - defined in Panevová 1974, 1978 as the set-theoretic sum of inner participants and semantically obligatory dependents. That is, arguments naturally fall into three sub-classes: semantically obligatory inner participants (including the deep subject), semantically optional inner participants, and semantically obligatory free adverbials.

The picture is actually a little more complicated in Panevová 1978, where another criterion is taken into account, namely, "semantic unity of modification". This leads to 8 theoretical possibilities (given that iterability is played down in that publication), summarised in Table 1. Panevová 1978, p. 234, states that "the combination of features

123

obligatoriness limited number semantic unity

\begin{tabular}{llll}
\hline 1 & + & + & + \\
2 & + & + & - \\
3 & + & - & + \\
4 & + & - & - \\
5 & - & + & + \\
6 & - & + & - \\
7 & - & - & + \\
8 & - & - & -
\end{tabular}

Table 1. Three criteria for AAD (from Panevová 1978, p. 233)

in the lines 4, 6 remain unrealized" and that "only such participants characterized in

\footnotetext{
${ }^{2}$ Our description of this test is based on that of Przepiórkowski et al. 2016.
} 
the matrix at least by two positive [i.e. +; AP] features belong to inner participants [i.e. arguments; AP]". Given these statements, it is not necessary to understand the notion of "semantic unity of modification" to see that it is redundant for the purposes of AAD: after removing lines 4 and 6, the lines with at least two + values are exactly the lines where at least one of columns 1 and 2 contains a + , i.e. the lines corresponding to the sum of semantically obligatory dependents and dependents passing the specificity test on inner participants. Hence, in the remainder of this paper we will not be concerned with the "semantic unity of modification", which also seems to play no role in FGD literature after Panevová 1978.

\section{Iterability}

Bresnan 1982b, p. 165, contrasts example (3) above with the following example, $\underline{\underline{3}}$ purportedly showing that instruments cannot be iterated:

(4) *John escaped from prison with dynamite [MEANs] with a machine gun [MEANs].

However, there is a clear difference between the repeated functors in the two examples: in (3), they refer to the same entity, while in (4), they refer to two different entities. In particular, dynamite and machine gun necessarily denote two different instruments, while both in a restaurant and in Back Bay refer - with different granularities - to the single location of the event. Similarly, there is a single time of the event described in (3), which is referred to via phrases over lunch, at noon and last Sunday, and - arguably - there is a single manner of handing a toy to the baby which may be variously characterised as deftly, by reaching behind his back and without interrupting the discussion.

Once this difference between (3) vs. (4) is acknowledged, it becomes less clear that there is any iterability contrast between different functors. For example, Goldberg (2002, pp. 334-335,341) argues that instrumental phrases may be iterated as long as they "concentrically" refer to the same entity, and supports this claim with the following examples: $-\underline{4}$

(5) With a slingshot he broke the window with a rock.

(6) The robot opened the door with a key with its robotic arm.

Another - perhaps more convincing - example of iterated arguments is mentioned in Zaenen and Crouch 2009, p. 646:

\footnotetext{
${ }^{3}$ Again, the original tag Inst is replaced here with the corresponding FGD functor MEANS.

${ }^{4}$ Within FGD, instruments are supposed to be freely iterable, as they are treated as free adverbials, but the only example of such iterability we have come across is not convincing. Panevová 2003, p. 2, provides the following Russian example, but it is controversial that both phrases marked as Instrument should bear the same semantic role (functor); na rojale, lit. 'on piano', should rather be classified as one of the core arguments of the verb IGRAT' 'play':

(i) Ivan umeet igrat' na rojale (Instrument) tol'ko pravoj rukoj (Instrument).

[Ivan can play a piano only with his right hand.]

(See also Sgall et al. 1986, p. 161, fn. 58, on the possibility of partitioning such a general Instrument role into more specific roles.)
} 
(7) I count on you, on your kindness.

As shown in (8), taken from Urešová 2011, p. 148, the PDT-Vallex valency dictionary of Czech (Hajič et al., 2003) based on FGD treats spoléHAT (NA), the Czech for 'count (on)', as taking a prepositional patient:

(8) spoléhat $\mathrm{ACT}(1) \operatorname{PAT}(n a+4 ; \downarrow z ̌ e)$

There seems to be no reason to assume that the corresponding phrases in (7) should bear a different functor, so this example involves a repetition of the patient functor, and the Czech and Polish facts are similar, as shown in (9) $-(\underline{10})$, which are literal translations of (7).

(9) Spoléhám na vás, na vaši laskavost.

(Czech)

(10) Liczę na was, na waszą życzliwość.

(Polish)

Hence, in all three languages, the sentences (7) and (9)-(10) should be analysed as exhibiting iteration of the (semantically obligatory) patient, i.e., a clear case of an inner participant (and a prototypical argument).

It is easy to construct examples of other iterated inner participants, for example, an iterated actor, as in the following Polish example, where the three nominative NPs are understood as referring to the same person:

(11) Ważny urzędnik wczoraj przyszedł, dyrektor departamentu, important.NOM official.NOM yesterday came director.NOM department.GEN bardzo wysoko postawiona osoba...

very highly placed person

'An important official came yesterday: the director of a/the department, a very high-ranking person.'

It could be argued that (ㅁ) and (9) $-(\underline{10})$, and maybe also (11), should be analysed as some special construction, perhaps a type of apposition. Perhaps so. But whatever the analysis of such examples of iterated inner participants, the burden is on the shoulders of the proponents of the dichotomy to show that this analysis does not carry over to examples of iterated free adverbials. Since we are not aware of such an argument, we conclude then that iterability, as currently understood, fails to distinguish inner participants from free adverbials and, hence, does not seem relevant for the Argument-Adjunct Distinction.

\section{Specificity}

Taken literally, the specificity test also gives undesirable results, as very few of the intended members of the class of free adverbials may really "depend on every verb". For example, McConnell-Ginet 1982, p. 166, notes that WEIGH fails to combine with many typical adverbials:

(12) * Annie weighs 120 pounds \{heavily / beautifully / quickly / elegantly\}.

(13) * Annie weighs 120 pounds ffor her mother / with a fork / in an hour / toward Detroit\}. 
Even such prototypical types of free adverbials as TwHEN (time) and LOC (location) are subject to exceptions. As shown in Koenig et al. 2003, p. 80, where an experiment consisting in the manual examination of 3909 English verbs is reported, $0.2 \%$ (i.e. 8) of them do not combine with dependents of type TwHEN and 1.8\% (i.e. as many as 70) do not combine with LOc. Matters are much worse in case of most other dependent types claimed (Panevová, 1974, p. 12) to occur with all verbs.

It is also clear that the results of this test depend on the granularity of functors. For example, simplifying a little, Koenig et al. 2003 treat as arguments those dependents which may occur with up to $30 \%$ of all verbs, and as adjuncts - those which may occur with at least $90 \%$ of all verbs. It seems then that agents should count as typical adjuncts. However, Koenig et al. 2003 avoid this conclusion by splitting this dependent type into more fine-grained semantic roles, as proposed in Dowty 1989, 1991, and showing that each of them occurs with less than $30 \%$ of the examined verbs.

Similar reasoning may be applied to durative dependents (THL, i.e., "temporal how long") - typical free adverbials. It is probably true that they may modify all or almost all verbs, including the class of verbs which Laskowski (1998) calls atemporal. However, not all durative dependents are alike, and it has been shown that prepositional durative phrases such as for two hours have different distribution and semantic implications than bare nominal durative phrases such as two hours even in languages such as English (Morzycki, 2005). Also in Slavic languages, the distribution of the two kinds of duratives differs, as the following Polish examples illustrate:
a. Janek tańczył przez dwie godziny.
Janek.NOM danced.IMPERF for two.ACC hours.ACC
'Janek was dancing for two hours.'
b. Janek ?*(tylko raz) zatańczył przezdwie godziny.
Janek.NOM only once.ACC danced.PERF for two.ACC hours.ACC
c. Janek ?(ani razu) nie zatańczył przez dwie godziny.
Janek.NOM not once.GEN NEG danced.PERF for two.ACC hours.ACC
'For two hours, Janek didn't dance.'
(15) a. Janek tańczył dwie godziny.
Janek.NOM danced.IMPERF two.ACC hours.ACC
'Janek was dancing for two hours.'
b. *Janek (tylko raz) zatańczył dwie godziny.
Janek.NOM only once.ACC danced.PERF for two.ACC hours.ACC
c. *Janek (ani razu) nie zatańczył dwie godziny.
Janek.NOM NEG danced.PERF two.ACC hours.ACC

The three examples in (14) show that prepositional PRZEZ+NP[ACC] duratives may combine with both imperfective and perfective verbs, although their semantic contribution to the sentence differs in these two cases. In (14a), which involves an imperfective verb, the natural understanding of the sentence is that the event of dancing lasted for two hours. This meaning is absent in $(14 b-c)$, which involve the perfective 
counterpart of that verb: they cannot mean that dancing lasted (in b.) or not lasted (in c.) for two hours. Rather, the durative PPs set the time frame, during which an event is said to occur once (however long it lasted - perhaps only a few minutes) or not occur at all. For this reason, the naturalness $(14 b-c)$ is greatly enhanced by dependents with meanings such as 'only once', 'a number of times' or 'not even once' - this is especially true about $(\underline{14 b})$.

On the other hand, as shown in (15), bare NP[ACC] seem not to have this time frame meaning, and may only refer to the duration of the event expressed by the verb - this explains the ungrammaticality of $(15 b-c)$, even in versions with added dependents meaning 'only once' or 'not even once'. Since the two types of durative dependents may contribute to the meaning of the sentence in different ways and, hence, have different distributions, they should be represented by different functors in a fully precise and explicit generative description; let us call these functors THL-PP ("prepositional temporal how long") and THL-NP ("bare nominal temporal how long"). Now, while THL-PP may still be claimed to be able to occur with all or almost all verbs (but with different meaning contribution, depending on the broadly understood aspectual characteristic of the verb - either as eventuality $\frac{5}{-}$ duration or time frame duration), THL-NP is confined to imperfective verbs, as well as delimitatives (Piernikarski, 1969; Bogusławski, 2004) and perhaps a limited number of other verbs, and always denotes eventuality duration. Adopting the prevailing view that in Slavic languages such as Czech or Polish aspect is lexicalised, i.e. that the imperfective and the perfective variants are two different lexemes, this means that such dependents will only combine with perhaps more than half of the verbs, but certainly very far from all of them, and yet they are considered typical free adverbials in FGD.

A similar point can also easily be made on the basis of various functors whose presence depends on whether the verb requires an agent (as is well known, many verbs do not, e.g. weather predicates or psych-verbs), e.g. the INTT (intent) functor and perhaps MEANS (instrument). The problem that many intended free adverbials do not really combine with various classes of verbs is duly noted in a footnote (fn. 6 in Panevová 1974 and fn. 13 in Panevová 1978), where it is stated that "it appears as a rule that such a combination is not grammatically excluded but is unusual due to cognitive or ontological reasons" (Panevová, 1978, p. 252). Unfortunately, this view makes the test largely unusable in practice, as there is no operational procedure of distinguishing "grammatical unacceptability" from "cognitive or ontological unacceptability". Moreover, it is not clear that such a distinction is justified at all; as shown in Levin 1993, grammatical behaviour of verbs (their diathesis patterns) strongly correlates with their meaning (which may be hard to distinguish from "cognitive or ontological" aspects).

In summary, very few classes of free adverbials, if indeed any, "can depend on every verb", and attempts to distinguish reasons for not satisfying this criterion have

\footnotetext{
${ }^{5}$ We use Emmon Bach's (1986) term here, which generalises events and states.
} 
never, to the best of our knowledge, been translated into an operational test, so the specificity criterion simply does not do the job it was supposed to do.

\section{Semantic obligatoriness}

The dialogue test has an interesting history. While it was first presented in Panevová 1974, pp.17-19, it was apparently inspired "by the method of 'given and new information', which was briefly sketched by Sgall and Hajičová $(1970, \S 3.1)$ " (Panevová, 1974, p. 16).

Sgall and Hajičová (1970, p. 17) critically discuss the view that clauses have a possibly implicit "time of the clause" semantic dependent, so that sentences such as $\mathrm{He}$ wrote all these books might be understood as talking about (at least) three entities: the agent, the patient and the time. But if this were so, the questions Who wrote them? and When did he? should be fully analogous: the wh-word should refer to an entity already introduced in the discourse. In other words, these questions should have the following meanings: Who do you mean? and What time do you mean?. However, while Who wrote them? may be understood as Who do you mean? in the context of the previously uttered He wrote all these books, the question When did he? cannot be paraphrased as What time do you mean?; for such a paraphrase to work, the original utterance should have been He wrote all these books then, or so. Hence, "time of the clause" is not an implicit semantically obligatory dependent in He wrote all these books. This should be contrasted with examples such as John returned. Here, Where from? also cannot be understood as What origin of the journey do you mean?, but Where to? may indeed be understood as What destination of the journey do you mean?.

On the other hand, it has remained hardly noticed that the property targeted by the dialogue test is also discussed in another thread of linguistic work, starting with Fillmore 1969. 6 The following sentences, among others, are discussed there, with some semantic roles (Fillmore's "deep cases") unrealised syntactically in the last two sentences (Fillmore, 1969, pp. 118-119):

(16) The boys blamed the girls for the mess.

(17) The boys blamed the girls.

(18) The girls were blamed for the mess.

In comparison with the complete sentence (16), the offence is missing in (17), and the accuser is absent in (18). However, these two implicit dependents have different kinds of interpretations in the two sentences. The last sentence, (18), is "a syntactically complete sentence, in the sense that it can appropriately initiate a discourse (as long as the addressee knows who the girls are and what the mess is). In this case the speaker is merely being indefinite or non-committal about the identity of the accuser" (Fillmore, 1969, p. 119). Hence, this sentence may be paraphrased as The girls were blamed

\footnotetext{
${ }^{6}$ Interestingly, Fillmore 1969 is cited in Sgall and Hajičová 1970 and in Panevová 1974, 1978, but in a different context.
} 
for the mess by someone. On the other hand, sentence (17) is "one which cannot initiate a conversation and one which is usable only in a context in which the addressee is in a position to know what it is that the girls are being blamed for" (ibid.). That is, it cannot be paraphrased as The boys blamed the girls for something, but rather as The boys blamed the girls for it. "The two situations correspond, in other words, to definite and indefinite pronominalization" (ibid.).

Fillmore 1969 does not have much more to say about this phenomenon, but the discussion in Fillmore 1986 makes it clear that the definite interpretation of the implicit dependent in (17) concerns the same phenomenon as the semantic obligatoriness picked out by the dialogue test. For example, when comparing the verb EAT, which allows for an indefinite implicit dependent, with FIND OuT, whose implicit dependent must be definite, Fillmore 1986, p. 96 says: “It's not odd to say things like, 'He was eating; I wonder what he was eating'; but it is odd to say things like 'They found out; I wonder what they found out'". This test very closely resembles the dialogue test, and it gives the same results. For example, in case of ARRIVE, it would be natural to say He arrived; I wonder where he arrived from, but the following sounds odd: He arrived; I wonder where he arrived.

This distinction between the two classes of implicit dependents has been widely discussed in the literature; some of this discussion is summarised in Williams 2015, ch.5, where the relation to the dialogue test is alluded to (pp.100-101). Such implicit dependents are carefully analysed in Recanati 2002, 2007 (his unarticulated constituents), where a position similar to that of FGD is adopted: definite implicit dependents, i.e. those classified as semantically obligatory by the dialogue test, are claimed to be present in the semantic structure of respective sentences, while the existential implicit dependents, i.e. those classified as optional by the dialogue test, are claimed to be absent from the semantic representation. On the other hand, according to Recanati $(2002,2007)$, such absent dependents may be added to the argument structure of the predicates via essentially pragmatic - context-dependent - processes. On this analysis, given that the $a$. and $b$. sentences below are synonymous, there is no difference between the direct object (and, hence, a prototypical argument in most theories) of EAT and the locative dependent of DANCE (a prototypical adjunct); in both cases the a. sentences have only one argument (the subject), and the b. sentences have two arguments:

(19) a. John is eating.

b. John is eating something or other.

(20) a. John is dancing.

b. John is dancing somewhere or other.

The situation is markedly different in case of verbs such as NOTICE and ARRIVE, where the $b$. sentences below are not synonymous with the a. sentences; better paraphrases are given in c.: 
(21) a. John noticed.

b. John noticed something or other.

c. John noticed it / the thing.

(22) a. John arrived.

b. John arrived somewhere or other.

c. John arrived there / at the destination.

Note that, when talking about arguments, Recanati $(2002,2007)$ completely disregards the distinction between inner participants and free adverbials.

The importance of Recanati 2002, 2007 for the current considerations lies in the discussion of difficulties in applying the dialogue test. $\frac{7}{-}$ At first sight it might seem that location is a semantically obligatory argument of RAIN, as the dialogue in (23) seems to pattern with the awkward (24) rather than with the natural (25):

(23) A: It is raining.

B: Where is it raining?

A: I have no idea.

(24) A: John has arrived.

B: Where has he arrived?

A: I have no idea.

(25) A: John has danced.

B: Where has he danced?

A: I have no idea.

However, Recanati (2002, p. 317) carefully constructs a context that makes a dialogue such as (23) sound natural:

I can imagine a situation in which rain has become extremely rare and important, and rain detectors have been disposed all over the territory... In the imagined scenario, each detector triggers an alarm bell in the Monitoring Room when it detects rain. There is a single bell; the location of the triggering detector is indicated by a light on a board in the Monitoring Room. After weeks of total drought, the bell eventually rings in the Monitoring Room. Hearing it, the weatherman on duty in the adjacent room shouts: 'It's raining!' His utterance is true, iff it is raining (at the time of utterance) in some place or other.

Translated to the dialogue test, this renders (Recanati, 2007, p. 129):

(26) A (the weatherman): It is raining!

B: Where?

A: I have no idea - let's check.

Hence, Recanati $(2002,2007)$ concludes that, contrary to the standard view in the kind of (philosophically inclined) literature he cites, RAIN has no semantically obligatory location argument; in case location is expressed in the sentence (as in It is raining in Paris), such an argument is added via a pragmatic process proposed in Recanati 2002. But in order to reach this conclusion, the first impression given by a straight-

\footnotetext{
${ }^{7}$ Other subtleties and "thorny questions" regarding the practical use of the dialogue test are discussed in Panevová 2001, §4. The fact that it is not always easy to apply the dialogue test when constructing a valency dictionary is also mentioned in Urešová 2006, p. 95, and in Przepiórkowski et al. 2016, p. 14.
} 
forward application of the dialogue test had to be rejected and a very specific context had to be constructed.

In fact, the discussion in the philosophical literature on the applicability of the dialogue test remains inconclusive, as it seems that - by constructing sufficiently unusual contexts - all implicit arguments should be considered semantically optional. In particular, Recanati 2010, p. 117, cites an anonymous Linguistics and Philosophy referee as providing the following context, which suggests that the object of NOTICE, apparently semantically obligatory on the straightforward application of the dialogue test, is in fact semantically optional:

Consider a scenario with a patient who has been in a semi-coma, and a technician in another room is reading the output of an EEG or whatever it is that measures brain activity in various areas of the brain. It seems to me that a trained technician could know when brain activity signals 'noticing', and since for the semi-coma patient, the fact that he's noticing (something) is all that's important, one might imagine the technician being able to shout 'He's noticing!' without being in any position to know or say what it is that the patient is noticing.

These considerations open the possibility that the dialogue test does not really distinguish between semantically obligatory and semantically optional constituents, and that the perceived obligatoriness is a perhaps graded function of context: in case of some dependents of some verbs it is easier to construct a context in which the dependent is understood existentially (i.e. as semantically optional), and in case of other it is more difficult to construct such a context, but perhaps it is always possible. In any case, in order to be truly operational, the dialogue test and the conditions in which it may be used should be further elaborated.

\section{Does FGD need AAD?}

Let us take stock. Functional Generative Description proposes two orthogonal classifications of dependents: into inner participants and free adverbials, and into semantically obligatory and semantically optional. The product of these classifications gives four classes, three of which - with the exception of semantically optional free adverbials - together constitute arguments, i.e. valency elements. This in itself is not unreasonable and it is interesting to note that a very similar idea is apparently independently proposed in Goldberg 2002, pp. 344-346, within the framework of Construction Grammar (Goldberg, 1995).

The distinction between semantically obligatory and semantically optional dependents, even if sometimes difficult to test, is widely assumed in contemporary linguistics. However, by itself this distinction does not correlate with the common understanding of the $\mathrm{AAD}$, as it distinguishes between the traditional complements of NOTICE and DEVOUR on one hand (they are semantically obligatory), and the traditional complements of EAT and SPEAK (to somebody) on the other (they are semantically optional). The other distinction, that between inner participants and free adverbials, 
while very close to AAD, is not operational as it stands: prototypical inner participants (including patients and actors) seem to be as iterable as prototypical free adverbials, and there are many exceptions to the intended results of the specificity test and no procedure of distinguishing "grammatical unacceptability" from "cognitive or ontological unacceptability" is in sight. Hence, also the combination of these two distinctions, used to differentiate between arguments and adjuncts in FGD, is not operational.

Problems with the binary AAD have been noticed in various theories, and the most common escape strategy is to posit an additional intermediate class, between arguments and adjuncts. Probably the best known example of an application of this strategy is the class of "argument adjuncts" (a-adjuncts) of Grimshaw 1990, ch. 4, encompassing optional dependents corresponding to subjects in active voice of verbs: by-phrases with passive verbs and certain possessive dependents of nominals. A more recent example is Needham and Toivonen 2011, which extends the intermediate class of "derived arguments" to various other types of dependents, including instruments and benefactives. The common feature of such "derived arguments" is that they seem to satisfy some of the tests for argumenthood and fail other such tests. The same approach is proposed in Panevová 2003 (see also Lopatková and Panevová 2006). An obvious problem with this strategy is that it replaces one vague distinction with two even vaguer distinctions.

Some theories have AAD hard-wired into their formalisms. This is the case with those versions of transformational theories (especially, the Government and Binding theory of 1980s; Chomsky 1981) that distinguish between arguments and adjuncts tree-configurationally (where, roughly, arguments are sisters to $X$ heads and adjuncts are sisters to $X^{\prime}$ projections, assuming Jackendoff's (1977) $\bar{X}$ syntax); this is also the case with Lexical Functional Grammar (Bresnan, 1982a; Dalrymple, 2001), which distinguishes argument grammatical functions from adjuncts within functional structures. - However, as far as we can tell, nothing within FGD seems to depend on this dichotomy. In particular, instead of distinguishing between arguments and adjuncts, all dependent types (FGD's functors) are treated uniformly in the formal FGD definitions of the basic component and the tectogrammatical representation (Sgall et al., 1986, pp. 150-153), where only the distinction between obligatory and optional dependents is implicit in the definitions of obligatory expansion rules. Also, in the discussion of the role of valency frames in Sgall et al. 1986, pp.158-159, semantic obligatoriness and iterability are referred to separately, the notion of argument apparently being superfluous. Similarly, no contentful reference to this dichotomy is made in the discussion of the systemic ordering (Sgall et al., 1986, pp. 194-203); in particular the ordering proposed for Czech (pp. 198-199) has argument functors intermingled with functors typical of adjuncts. Further, no reference to arguments or adjuncts as a class is made in ch. 4 of Sgall et al. 1986, where correspondences between linguistic levels are dis-

\footnotetext{
${ }^{8}$ But see Przepiórkowski 2016 for a voice of dissent.
} 
cussed; etc. So it seems that the benefit of maintaining the AAD is purely practical: when describing the potential of particular predicates to combine with various kinds of dependents, some combinations seem more idiosyncratic or perplexing than other, so some dependents (let us call them arguments) should be explicitly mentioned in the lexical entry of a given predicate, and other (let us call them adjuncts) may be assumed to be sufficiently predictable to be omitted from such lexical entries.

But it is not clear that, when carefully examined, any types of dependents are sufficiently regular to be excluded from the lexicon: as mentioned above, out of 3909 English verbs carefully examined by two independent annotators, some 1.8\% (about 70) apparently do not combine with one of the most prototypical types of adjuncts, namely, that of event location; the existence of various exceptions of this kind is also mentioned - but played down - in FGD work on valency; some types of traditional adjuncts seem to depend on the grammatical or lexical aspect of the verb (in Slavic); etc. Hence, the current approaches to valency lexicons may be viewed as only first approximations of future full-fledged valency dictionaries containing information about all dependent types (i.e. functors): whether they are possible at all (some predicates will not combine with some types of dependents at all), whether they are semantically obligatory, to what extent they are iterable, under what conditions they may accompany the predicate, etc. Obviously, developing such a dictionary would require much more work, as all functors would have to be examined in case of each predicate, not just those that spring to mind as specific to this predicate. Let us imagine that such a dictionary exists, organised just as the Czech FGD valency dictionary PDT-Vallex but not assuming any fundamental distinction between two classes of dependents. We believe that this dictionary would still count as an FGD dictionary and that it would not violate any fundamental FGD principles. If so, FGD does not really need the ill-defined Argument-Adjunct Distinction and would be a more precise and parsimonious theory without it; after all, one of the two fundamental working principles of FGD is that (Sgall et al., 1986, p. 101):

the number of elementary units on the tectogrammatical level should be as small as possible, so that clear reasons can be given for every newly recognized unit or distinction.

As argued above, such a clear reason is lacking for the Argument-Adjunct Distinction.

\section{Acknowledgements}

Many thanks to Jadwiga Linde-Usiekniewicz, Jarmila Panevová, Agnieszka Patejuk and Zdeňka Urešová for their comments on previous versions of this paper, and to Magdalena Danielewiczowa, Leonid Iomdin, Václava Kettnerová, Jadwiga LindeUsiekniewicz, Jarmila Panevová and Alexandr Rosen for their questions and comments after the presentation of this paper at a valency conference in Warsaw in June 2016. Thanks are also due to two anonymous reviewers of PBML, whose comments have led to numerous improvements. This research is partially supported by 
the Polish Ministry of Science and Higher Education within the CLARIN ERIC programme 2015-2016 (http: //clarin.eu/) and by the IC 1207 COST Action PARSEME (http://www. parseme.eu/).

\section{Bibliography}

Bach, Emmon. The Algebra of Events. Linguistics and Philosophy, 9:5-16, 1986.

Bogusławski, Andrzej. Small is Beautiful. A Note on Verbs of Small Events. In Tipologiceskie obosnovanija v grammatike. K 70-letiju professora V.S. Chrakovskogo, pages 61-75. Znak, Moscow, 2004.

Bresnan, Joan, editor. The Mental Representation of Grammatical Relations. MIT Press Series on Cognitive Theory and Mental Representation. The MIT Press, Cambridge, MA, 1982a.

Bresnan, Joan. Polyadicity. In The Mental Representation of Grammatical Relations Bresnan (1982a), pages 149-172.

Chomsky, Noam. Lectures on Government and Binding. Foris, Dordrecht, 1981.

Dalrymple, Mary. Lexical Functional Grammar. Academic Press, San Diego, CA, 2001.

Dowty, David. On the Semantic Content of the Notion of 'Thematic Role'. In Chierchia, Gennero, Barbara H. Partee, and Raymond Turner, editors, Properties, Types and Meaning: II, pages 69-129. Kluwer, Dordrecht, 1989.

Dowty, David. Thematic Proto-roles and Argument Selection. Language, 67(3):547-619, 1991.

Fillmore, Charles J. Types of Lexical Information. In Kiefer, Ferenc, editor, Studies in Syntax and Semantics, pages 109-137. Reidel, Dordrecht, 1969.

Fillmore, Charles J. Pragmatically Controlled Zero Anaphora. In Proceedings of the Twelfth Annual Meeting of the Berkeley Linguistics Society, pages 95-107, Berkeley, 1986. Berkeley Linguistics Society.

Goldberg, Adele E. Constructions: A Construction Grammar Approach to Argument Structure. Chicago University Press, Chicago, IL, 1995.

Goldberg, Adele E. Surface Generalizations: An Alternative to Alternations. Cognitive Linguistics, 13(4):327-356, 2002.

Grimshaw, Jane. Argument Structure. Linguistic Inquiry Monographs. The MIT Press, Cambridge, MA, 1990.

Hajič, Jan, Jarmila Panevová, Zdeňka Urešová, Alevtina Bémová, Veronika Kolářová, and Petr Pajas. PDT-VALLEX: Creating a Large-coverage Valency Lexicon for Treebank Annotation. In Nivre, Joakim and Erhard Hinrichs, editors, Proceedings of the Second Workshop on Treebanks and Linguistic Theories (TLT 2003), Växjö, Norway, 2003.

Jackendoff, Ray. $\bar{X}$ Syntax: A Study of Phrase Structure. The MIT Press, Cambridge, MA, 1977.

Koenig, Jean-Pierre, Gail Mauner, and Breton Bienvenue. Arguments for Adjuncts. Cognition, 89:67-103, 2003.

Larson, Richard. Bare NP adverbs. Linguistic Inquiry, 16:595-621, 1985. 
Laskowski, Roman. Kategorie morfologiczne języka polskiego - charakterystyka funkcjonalna. In Grzegorczykowa, Renata, Roman Laskowski, and Henryk Wróbel, editors, Gramatyka współczesnego języka polskiego: Morfologia, pages 151-224. Wydawnictwo Naukowe PWN, Warsaw, 2nd edition, 1998.

Levin, Beth. English Verb Classes and Alternations: A Preliminary Investigation. University of Chicago Press, Chicago, 1993.

Lopatková, Markéta and Jarmila Panevová. Recent Developments in the Theory of Valency in the Light of the Prague Dependency Treebank. In Šimková (2006), pages 83-92.

McConnell-Ginet, Sally. Adverbs and Logical Form: A Linguistically Realistic Theory. Language, 58(1):144-184, 1982.

Morzycki, Marcin. Mediated Modification: Functional Structure and the Interpretation of Modifier Position. Ph.D. Thesis, University of Massachusetts, Amherst, 2005.

Needham, Stephanie and Ida Toivonen. Derived Arguments. In Butt, Miriam and Tracy Holloway King, editors, The Proceedings of the LFG'11 Conference, pages 401-421, Stanford, CA, 2011. CSLI Publications. URL http://cslipublications . stanford .edu/LFG/16/lfgl1. html.

Panevová, Jarmila. On Verbal Frames in Functional Generative Description. Part 1. The Prague Bulletin of Mathematical Linguistics, 22:3-40, 1974.

Panevová, Jarmila. Inner Participants and Free Adverbials. Prague Studies in Mathematical Linguistics, 6:227-254, 1978.

Panevová, Jarmila. Valency Frames: Extension and Re-examination. In Chrakovskij, Viktor S., Maciej Grochowski, and Gerd Hentschel, editors, Studies on the Syntax and Semantics of Slavonic Languages. Papers in Honour of Andrzej Bogusławski on the Occasion of his 70th Birthday, pages 325-340. BIS, Oldenburg, 2001.

Panevová, Jarmila. Some Issues of Syntax and Semantics of Verbal Modifications. In Proceedings of MTT 2003 - First International Conference on Meaning-Text Theory, 2003. http: //meaningtext. net/mtt2003/proceedings/13. Panevova.pdf.

Piernikarski, Cezar. Typy opozycji aspektowych czasownika polskiego na tle słowiańskim. Ossolineum, Polska Akademia Nauk, Komitet Słowianoznawstwa, Warsaw, 1969.

Przepiórkowski, Adam. How not to Distinguish Arguments from Adjuncts in LFG. Paper delivered at HeadLex16 (Joint 2016 Conference on Head-driven Phrase Structure Grammar and Lexical Functional Grammar), to appear in the CSLI on-line proceedings, 2016.

Przepiórkowski, Adam, Jan Hajič, Elżbieta Hajnicz, and Zdeňka Urešová. Phraseology in two Slavic Valency Dictionaries: Limitations and Perspectives. International Journal of Lexicography, 29, 2016. URL http://ijl.oxfordjournals.org/content/early/2016/02/22/ijl. ecv048. abstract?keytype $=$ ref\&ijkey=jWNJn7Cxf7WJRhD. Forthcoming.

Recanati, François. Unarticulated Constituents. Linguistics and Philosophy, 25:299-345, 2002.

Recanati, François. It is raining (somewhere). Linguistics and Philosophy, 30:123-146, 2007.

Recanati, François. Truth-Conditional Pragmatics. Clarendon Press, Oxford, 2010.

Sgall, Petr and Eva Hajičová. A "Functional" Generative Description. The Prague Bulletin of Mathematical Linguistics, 14:9-37, 1970. 
Sgall, Petr, Eva Hajičová, and Jarmila Panevová. The Meaning of the Sentence in Its Semantic and Pragmatic Aspects. Reidel, Dordrecht, 1986.

Šimková, Mária, editor. Insight into Slovak and Czech Corpus Linguistics. Veda, Bratislava, 2006.

Tesnière, Lucien. Éléments de Syntaxe Structurale. Klincksieck, Paris, 1959.

Urešová, Zdeňka. Verbal Valency in the Prague Dependency Treebank from the Annotator's Viewpoint. In Šimková (2006), pages 93-112.

Urešová, Zdeňka. Valenční slovník Pražského závislostního (PDT-Vallex). Ústav formální a aplikované lingvistiky, Prague, 2011.

Williams, Alexander. Arguments in Syntax and Semantics. Cambridge University Press, 2015.

Zaenen, Annie and Dick Crouch. OBLs Hobble Computations. In Butt, Miriam and Tracy Holloway King, editors, The Proceedings of the LFG'09 Conference, pages 644-654, Trinity College, Cambridge, UK, 2009. CSLI Publications. URL http://cslipublications.stanford.edu/ LFG/14/index. shtml.

Žabokrtský, Zdeněk. Valency Lexicon of Czech Verbs. Ph.D. Thesis, Charles University, Prague, 2005.

\section{Address for correspondence:}

Adam Przepiórkowski

adamp@ipipan.waw.pl

Instytut Podstaw Informatyki PAN

ul. Jana Kazimierza 5

01-248 Warszawa

Poland 